\title{
Metal Concentrations in Soil Paste Extracts as Affected by Extraction Ratio
}

Filip M.G. Tack*, Nic Dezillie, and Marc G. Verloo

Laboratory of Analytical Chemistry and Applied Ecochemistry, Ghent University, Coupure Links 653, B-9000 Gent, Belgium

Saturated paste extracts are sometimes used to estimate metal levels in the soil solution. To assess the significance of heavy-metal concentrations measured in saturation extracts, soil paste extracts were prepared with distilled water in amounts ranging from $60-200 \%$ of the moisture content at saturation. Trace metals behaved as if a small pool consistently was dissolved independent of the extraction ratio applied. Metal concentrations in the solution hence were not buffered by the solid phase, but the observed behaviour would allow the estimation of metal concentrations in the soil solution as a function of moisture content. The behaviour of iron and manganese suggested that some microbial reduction occurred. The intensity increased with increasing extraction ratio but not to the extent of affecting dissolution of trace elements.

KEY WORDS: heavy metals, soils, soil solution, mobility, saturated paste extract

DOMAINS: agronomy, soil systems, environmental chemistry, bioremediation and bioavailability, environmental monitoring

\section{INTRODUCTION}

Potential adverse effects of heavy metals are most likely determined by their contents in the soil solution. With respect to plant uptake, it is assumed that the activity of the free metal ion in solution largely governs metal contents in crops[1,2]. In contaminated soils, leaching phenomena and the related risk of groundwater contamination are directly proportional to the concentrations in the soil solution, which in turn are determined by the physicochemical soil environment $[3,4]$.

Although highly desirable in environmental research, sampling the true soil solution without altering its chemistry is faced with difficulties. Saturated paste extracts may provide a more practical alternative to obtain information about the soil solution. A saturated paste extraction of a soil is a method originally developed to determine salts in soils[5], but workers in heavy-metal research also have relied on it to obtain a reflection of metal levels in the soil solution $[4,6,7,8,9,10,11,12]$. 
TABLE 1

Characteristics of the Investigated Soil

\begin{tabular}{cc}
\multicolumn{2}{c}{ Soil Properties } \\
$\mathrm{pH}$ & 8.1 \\
Organic matter & $1.1 \%$ \\
$\mathrm{CaCO}_{3}$ & $4.9 \%$ \\
$0-2 \mu \mathrm{m}$ & $9.4 \%$ \\
$2-50 \mu \mathrm{m}$ & $16.4 \%$ \\
$50 \mu \mathrm{m}$ to $2 \mathrm{~mm}$ & $74.2 \%$ \\
Trace Metal Contents (mg kg $^{-1} \mathbf{D M}$ ) \\
$\mathrm{Cd}$ & 0.6 \\
$\mathrm{Cu}$ & 25.8 \\
$\mathrm{~Pb}$ & 49.1 \\
$\mathrm{Zn}$ & 196 \\
$\mathrm{Mn}$ & 490
\end{tabular}

The aim of this work was to investigate how heavy-metal concentrations in an aqueous extract are affected by the extraction ratio. This may provide more insight into the factors controlling metal concentrations in the soil solution and, from a practical point of view, may enhance our understanding of the significance of heavy-metal concentrations measured in saturation extracts.

\section{MATERIALS AND METHODS}

A surface soil was sampled in August 2000 from a confined, dredged-sediment disposal site in Menen, Belgium[13]. Disposal of dredged sediments ceased in 1994. The sampled location was fallow land covered with herbs and grasses. Soil was sampled from $20-40 \mathrm{~cm}$ using an auger corer, air dried, and passed through a 2-mm sieve. Selected properties and elemental contents of the soil are presented in Table 1.

The soil was subjected to extractions with deionised water. The basic procedure was the extraction of a saturated paste as described by Jackson[5], with variation in the amounts of water added for extraction. These amounts corresponded to $60,80,90,100,120$, and $200 \%$ of the saturation point of the soil $\left(255 \mathrm{ml} \mathrm{kg}^{-1}\right.$ dry soil). The soil was allowed to equilibrate during $12 \mathrm{~h}$. The solution was obtained by vacuum filtration on a Büchner filter fitted with filter paper. A portion of the obtained liquid was filtered through an acid-rinsed $0.45-\mu \mathrm{m}$ membrane filter and acidified to $\mathrm{pH} 2$ using concentrated ultrapure $\mathrm{HNO}_{3}$ for analysis of the metals. The remaining extract was conserved at $3^{\circ} \mathrm{C}$ for at most $12 \mathrm{~h}$ before analysis of the anions with ion chromatography (Dionex Corp., Sunnyvale, CA).

Soil metal contents are pseudototal contents as determined by aqua-regia digestion[14]. Metals were determined by flame atomic absorption (Varian SpectrAA-10, Palo Alto, CA) equipped with deuterium correction or with graphite furnace equipped with Zeeman background correction (Varian SpectrAA-100, Palo Alto, CA). Quality was controlled by the analysis of duplicates, procedural blanks, and standard reference materials (estuarine sediment CRM 277 and light sandy soil CRM 142 R). Soil pH was determined in the saturation extract. Calcium carbonate was determined by acid-base titrimetry[15]. Organic carbon was measured using the method of Walkley and Black and expressed as organic matter using the factor 1.72[16]. Particle-size analysis was performed by conventional dry and wet seeving after destruction of organic matter and carbonates[17]. 

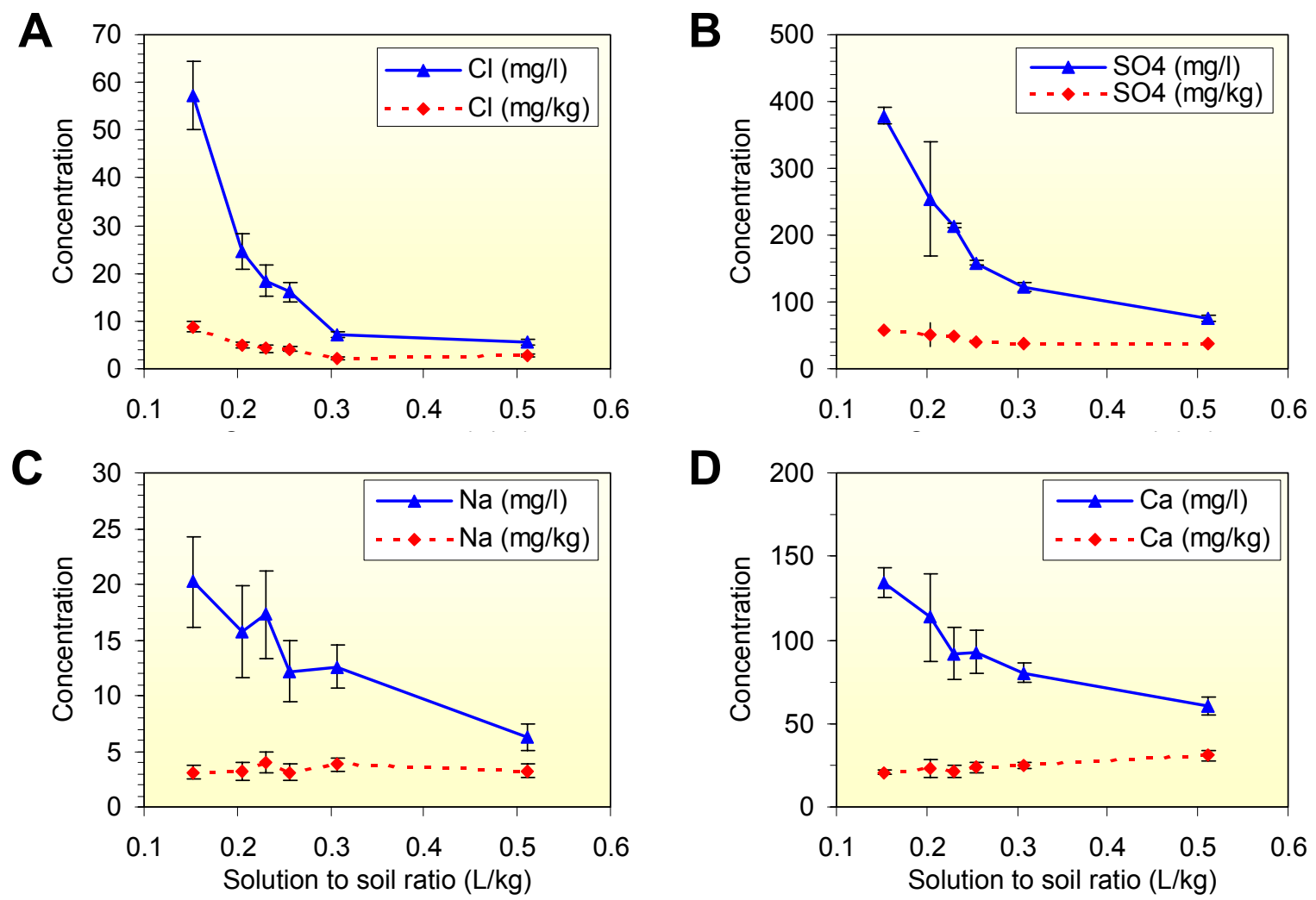

FIGURE 1. Concentrations in aqueous extracts (solid lines) and extracted amounts (dotted lines) of $\mathrm{Cl}^{-}, \mathrm{SO}_{4}{ }^{2-}, \mathrm{Na}$, and $\mathrm{Ca}$ as a function of extraction ratio. Error bars denote the standard deviation $(n=3)$.

\section{RESULTS AND DISCUSSION}

The soil was characterised as a sandy loam according to the USDA texture classification[18]. The soil $\mathrm{pH}$ was rather high at 8.1. This is consistent with the presence of free carbonates. Contents of copper were within normal ranges for soils with a similar clay and organic carbon content in Flanders, Belgium (18-30 mg kg${ }^{-1}$ )[19]. The other elements were slightly elevated, about two times higher than normal baseline concentration levels for cadmium and lead (0.1-0.4 and 18-28 $\mathrm{mg} \mathrm{kg}{ }^{-1}$, respectively) and about four times higher for zinc (32-45 $\mathrm{mg} \mathrm{kg}^{-1}$ ) (Table 1).

The experimental data show that for most elements, concentration decreased hyperbolically with increasing amount of water used for extraction (Figs. 1 to 3 ). When expressed on the basis of dry soil, extracted quantities of the elements remained constant. The system therefore behaved largely as if a water-soluble pool of elements consistently is released into solution independent of the moisture content during extraction.

This behaviour implies that the solid phase is not buffering metal concentrations in the solution. Soil solution metal concentrations in the field could therefore be expected to vary significantly with the moisture content for this soil. This will be an important factor in determining the actual mobility and availability of metals in the field and may need more consideration to improve the quality of risk assessment. Clearly, concentrations measured in the saturated paste extract will be different from concentrations in the actual soil solution. The observed behaviour, however, allows the easy estimation of metal concentrations in the soil solution as a function of soil moisture content from a single determination of metal concentrations in the saturation extract. There is a great need to investigate other soils in a similar way. 

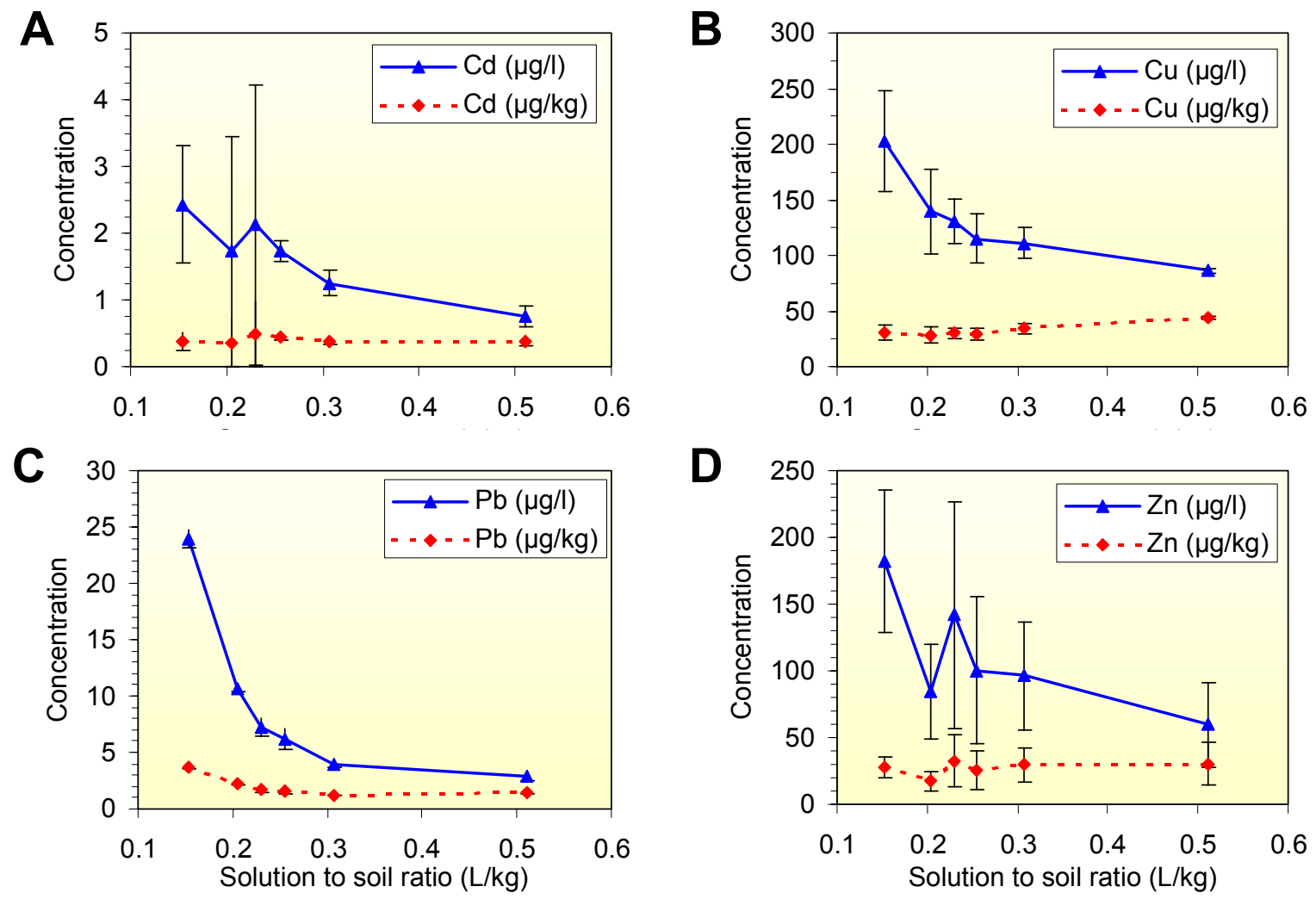

FIGURE 2. Concentrations in aqueous extracts (solid lines) and extracted amounts (dotted lines) of $\mathrm{Cd}, \mathrm{Cu}, \mathrm{Pb}$, and $\mathrm{Zn}$ as a function of extraction ratio. Error bars denote the standard deviation $(n=3)$.

Calcium concentrations decreased with increasing extraction ratio (L/S ratio); but expressed per kilogram of soil, amounts extracted increased slightly rather than remaining constant (Fig. 1D). This behaviour is not consistent with the observation that the soil contained $5 \%$ of free carbonates. From thermodynamics, it would be expected that with increasing extraction ratio, increasing amounts of $\mathrm{CaCO}_{3}$ would go into solution to meet the solubility product of soil $\mathrm{CaCO}_{3}[20]$. The system in true thermodynamic equilibrium should therefore exhibit rather constant calcium concentrations with increasing $\mathrm{L} / \mathrm{S}$ ratio. The currently observed behaviour reflects kinetic constraints. At $\mathrm{pH}=7.2$, or a proton concentration of $10^{-7.2} \mathrm{~mol} \mathrm{l}^{-1}$, dissolution of calcium carbonates may indeed proceed very slowly.

For iron and manganese, extracted amounts increased strongly with extraction ratio (Fig. 3 ). This can be accounted for by microbial reduction processes. It is observed from the graph that the increase was pronounced for extraction ratios above the saturation point of the soil. Saturated and oversaturated moisture conditions will favour the occurrence of anoxic zones and result in an increasingly important reduction of iron and manganese after $12 \mathrm{~h}$ of equilibration. Iron manganese oxides play a very important role in metal retention in soils[21], and reduction of these phases therefore may initially result in a release of metals. In the current experiment, extracted iron and manganese remained very limited compared to total amounts, which may be the reason that there was not yet a significant effect on the trace metals. Even though locally reducing zones may occur after $12 \mathrm{~h}$, the saturated soil paste remained essentially oxic. Tack et al.[4] observed that strongly reducing conditions were being established after about five consecutive saturated paste extractions. 

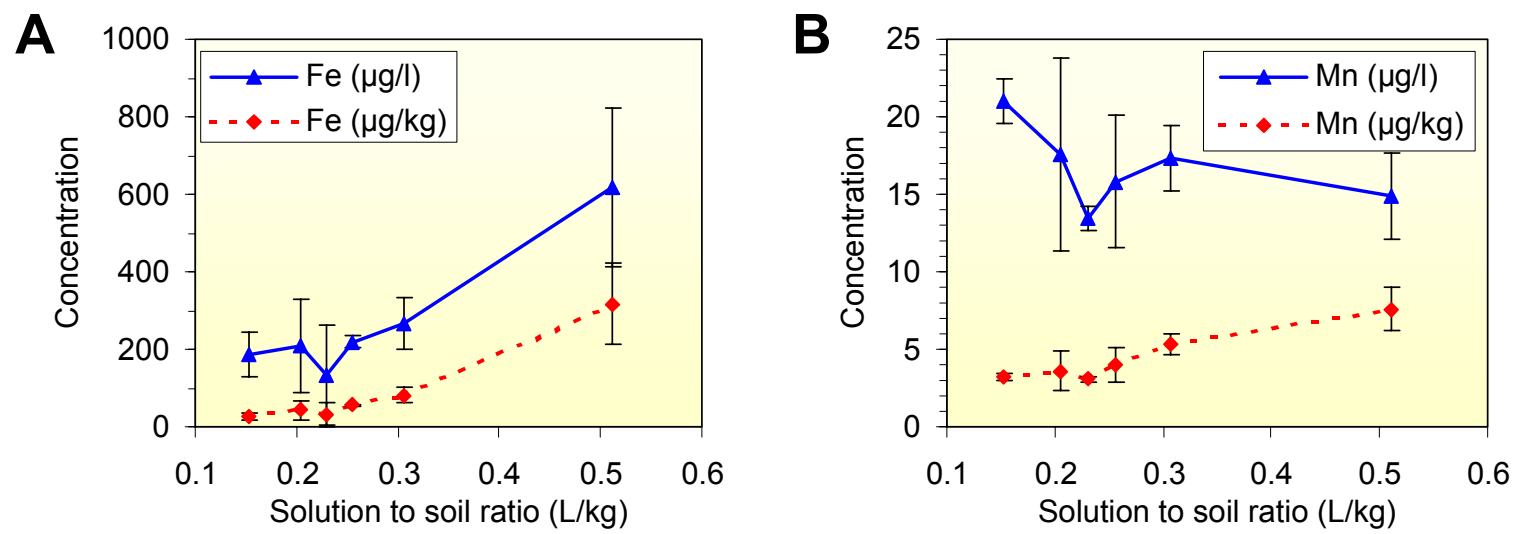

FIGURE 3. Concentrations in aqueous extracts (solid lines) and extracted amounts (dotted lines) of Fe and Mn as a function of extraction ratio. Error bars denote the standard deviation $(n=3)$.

The current experiment allowed a better appreciation of the practical significance of metal concentrations in a saturated paste extract. It is important to note that concentrations in the soil solution may not be effectively buffered by the soil solution. This may lead to significant variations in metal concentrations in the soil solution, which may have implications on environmental risk assessment, as it will affect the extent of leaching or plant uptake. Conclusions may not be generalised, however, before more soils have been investigated in a similar way.

\section{REFERENCES}

1. Sposito, G. (1984) The future of an illusion: ion activities in soil solutions. Soil Sci. Soc. Am. J. 48, 531536.

2. del Castilho, P. and Chardon, W.J. (1995) Uptake of soil cadmium by three field crops and its prediction by a pH-dependent Freundlich sorption model. Plant Soil 171, 263-266.

3. Moolenaar, S.W., Temminghoff, E.J.M., and De Haan, F.A.M. (1998) Modeling dynamic copper balances for a contaminated sandy soil following land use change from agriculture to forestry. Environ. Pollut. 103, $117-125$.

4. Tack, F.M.G., Singh, S.P., and Verloo, M.G. (1998) Heavy metal concentrations in consecutive saturation extracts of dredged sediment derived surface soils. Environ. Pollut. 103, 109-115.

5. Jackson, M.L. (1965) Soil Chemical Analysis. Prentice-Hall, Englewood Cliffs, NJ.

6. Verloo, M., Willaert, G., Eeckhout, M., and De Spiegeleer, F. (1987) Chemical and biological implications of metal speciation in contaminated soils. In Proceedings of the International Conference on Heavy Metals in the Environment, New Orleans. Part 1. CEP Consultants, Edinburgh. pp. 253-255.

7. Salam, A.K. and Helmke, P.A. (1998) The $\mathrm{pH}$ dependence of free ionic activities and total dissolved concentrations of copper and cadmium in soil solution. Geoderma 83, 281-291.

8. Canet, R., Pomares, F., and Tarazona, F. (1997) Chemical extractability and availability of heavy metals after seven years application of organic wastes to a citrus soil. Soil Use Manage. 13, 117-121.

9. Mahler, R.J., Bingham, F.T., Sposito, G., and Page, A.L. (1980) Cadmium-enriched sewage-sludge application to acid and calcareous soils: relation between treatment, cadmium in saturation extracts, and cadmium uptake. J. Environ. Qual. 9, 359-364.

10. Candelaria, L.M., Chang, A.C., and Amrhein, C. (1995) Measuring cadmium ion activities in sludgeamended soils. Soil Sci. 159, 162-175.

11. Albaladejo, J., Stocking, M., Diaz, E., and Castillo, V. (1994) Land rehabilitation by urban refuse amendments in a semiarid environment: effect on soil chemical properties. Soil Technol. 7, 249-260.

12. Helal, H.M., Haque, S.A., Ramadan, A.B., and Schnug, E. (1996) Salinity heavy metal interactions as evaluated by soil extraction and plant analysis. Commun. Soil Sci. Plant Anal. 27, 1355-1361.

13. De Vos, B. (1993) Rapport Leie/Menen. Report. Laboratorium voor Bosbouw, Gent, Belgium. 
14. Ure, A.M. (1990) Methods of analysis for heavy metals in soils. In Heavy Metals in Soils. Alloway, B.J., Ed. Blackie and Son, Glasgow. pp. 40-73.

15. Nelson, R.E. (1982) Carbonate and gypsum. In Methods of Soil Analysis. Part 2. Chemical and Microbiological Properties. Page, A.L., Miller, R.H., and Keeney, D.R., Eds. American Society of Agronomy, Madison, WI. pp. 181-197.

16. Nelson, D.W. and Sommers, L.E. (1982) Total carbon, organic carbon, and organic matter. In Methods of Soil Analysis. Part 2. Chemical and Microbiological Properties. Page, A.L., Miller, R.H., and Keeney, D.R., Eds. American Society of Agronomy, Madison, WI. pp. 539-579.

17. Gee, G.W. and Bauder, J.W. (1986) Particle-size analysis. In Methods of Soil Analysis. 2nd ed. Klute, A., Ed. American Society of Agronomy, Madison, WI, chap. 15.

18. U.S. Soil Conservation Service. (1962) Soil Survey Manual. U.S. Government Printing Office, Washington D.C.

19. Tack, F.M.G., Verloo, M.G., Vanmechelen, L., and Van Ranst, E. (1997) Baseline concentration levels of trace elements as a function of clay and organic carbon contents in soils in Flanders (Belgium). Sci. Total Environ. 201, 113-123.

20. Lindsay, L.W. (1979) Chemical Equilibria in Soils. John Wiley \& Sons, New York.

21. Jenne, E.A. (1968) Controls on $\mathrm{Mn}, \mathrm{Fe}, \mathrm{Co}, \mathrm{Ni}, \mathrm{Cu}$, and $\mathrm{Zn}$ concentrations in soils and water: the significant role of hydrous Mn and Fe oxides. Adv. Chem. Ser. 73, 337-387.

This article should be referenced as follows:

Tack, F.M.G., Dezillie, N., and Verloo, M.G. (2002) Metal concentrations in soil paste extracts as affected by extraction ratio. TheScientificWorldJOURNAL 2, 966-971.

\section{Handling Editor:}

James N. Galloway, Principal Editor for Environmental Chemistry — a domain of TheScientificWorldJOURNAL. 


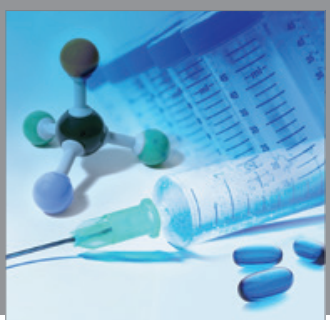

International Journal of

Medicinal Chemistry

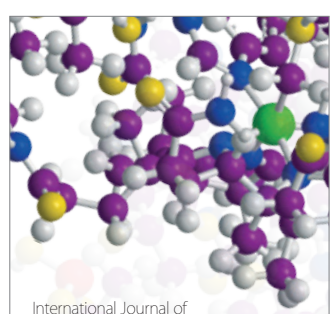

Carbohydrate Chemistry

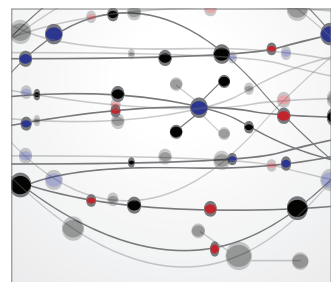

The Scientific World Journal
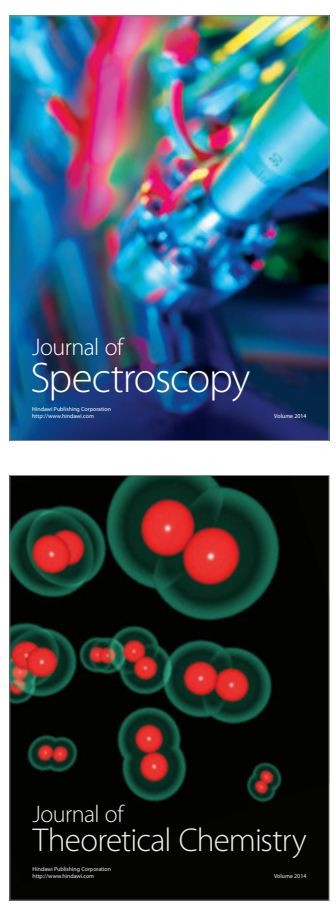
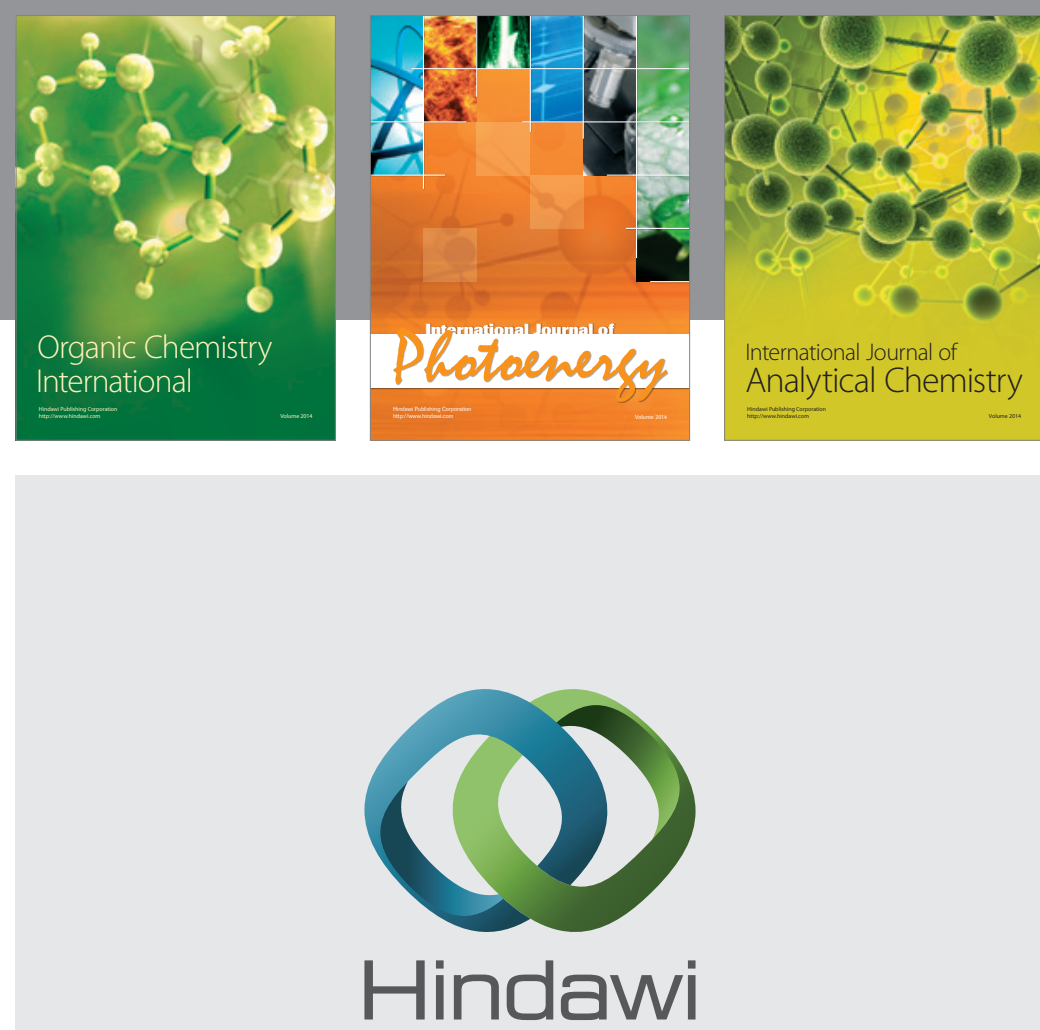

Submit your manuscripts at

http://www.hindawi.com
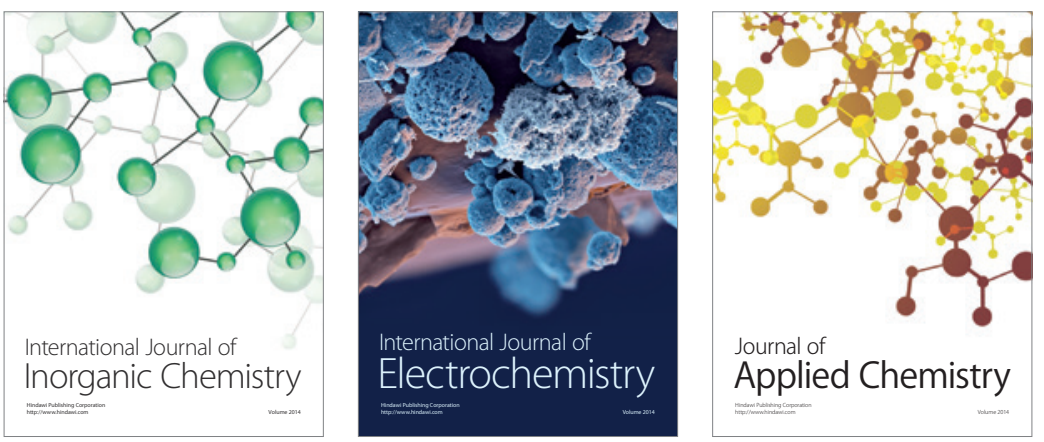

Journal of

Applied Chemistry
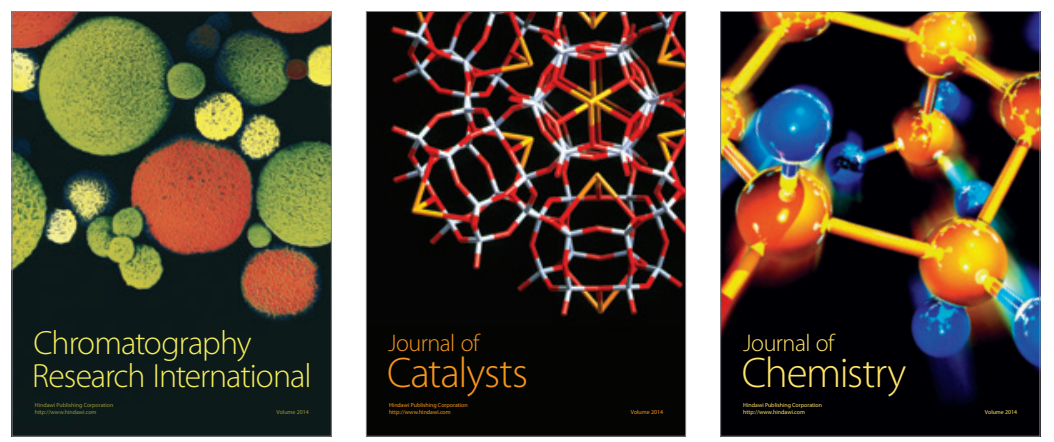
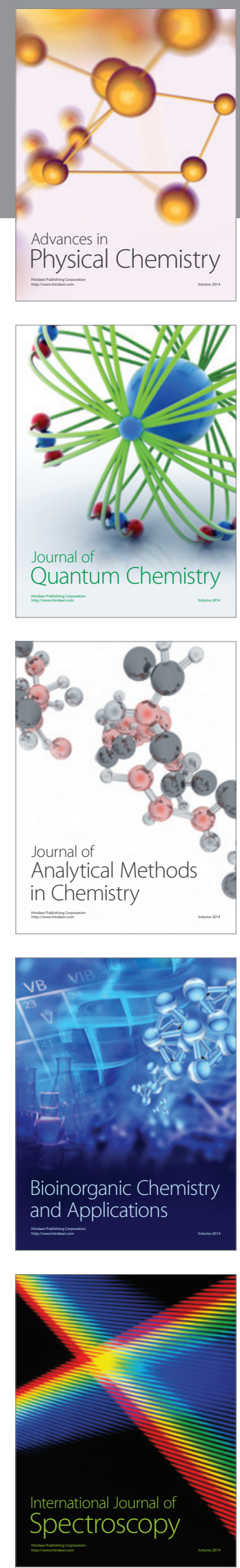